\title{
Reactive oxygen species induced by therapeutic CD20 antibodies inhibit natural killer cell-mediated antibody-dependent cellular cytotoxicity against primary CLL cells
}

\author{
Olle Werlenius ${ }^{1,2}$, Johan Aurelius ${ }^{1,2}$, Alexander Hallner ${ }^{2}$, Ali A. Akhiani², Maria \\ Simpanen ${ }^{2}$, Anna Martner ${ }^{2}$, Per-Ola Andersson ${ }^{3}$, Kristoffer Hellstrand ${ }^{2}$ and Fredrik \\ B. Thorén ${ }^{2}$ \\ ${ }^{1}$ Department of Hematology, Sahlgrenska University Hospital, Gothenburg, Sweden \\ 2 TIMM Laboratory, Sahlgrenska Cancer Center, University of Gothenburg, Gothenburg, Sweden \\ 3 Department of Medicine, Södra Älvsborgs Hospital, Borås, Sweden \\ Correspondence to: Fredrik B. Thorén, email: fredrik.thoren@gu.se
}

Keywords: monoclonal antibodies, reactive oxygen species, immunotherapy, NK cells, NOX2

Received: March 31, 2016

Accepted: April 03, 2016

Published: April 16, 2016

\section{ABSTRACT}

The antibody-dependent cellular cytotoxicity (ADCC) of natural killer (NK) cells is assumed to contribute to the clinical efficacy of monoclonal antibodies (mAbs) in chronic lymphocytic leukemia (CLL) and other hematopoietic malignancies of B cell origin. We sought to determine whether reactive oxygen species (ROS)-producing monocytes regulate the ADCC of NK cells against primary CLL cells using anti-CD20 as the linking antibody. The monoclonal CD20 antibodies rituximab and ofatumumab were found to trigger substantial release of ROS from monocytes. Antibody-exposed monocytes induced NK cell apoptosis and restricted NK cell-mediated ADCC against autologous CLL cells. The presence of inhibitors of ROS formation and scavengers of ROS preserved NK cell viability and restored NK cell-mediated ADCC against primary CLL cells. We propose that limiting the antibody-induced induction of immunosuppressive ROS may improve the anti-leukemic efficacy of anti-CD20 therapy in CLL.

\section{INTRODUCTION}

Subsets of cytotoxic leukocytes, including myeloid cells and NK cells, carry different Fc $\gamma$-receptors (Fc $\gamma \mathrm{R}$ ) and may thus attach the Fc portion of $\operatorname{IgG}$ antibodies to exert cytotoxicity against cells expressing a specific antigen [1]. ADCC is assumed to contribute to the clinical benefit of antibodies against $\mathrm{CD} 20$, such as rituximab (RTX) and ofatumumab (OFA), in B cell malignancies, and recent studies support that $\mathrm{F} c \gamma \mathrm{R}^{+} \mathrm{NK}$ cells are pivotal for the anti-leukemic efficacy [2-4]. Several authors report, however, that the NK cell population is functionally deficient in CLL $[5,6]$, and defining mechanisms of immunosuppression in this disease may be helpful in understanding the immunobiology of CLL and may have therapeutic implications.
Myeloid cells, such as monocytes and neutrophils, harbor the NOX2-containing NADPH oxidase, which is a multi-component enzyme complex that transfers electrons to molecular oxygen to generate superoxide anion and other ROS. These highly reactive compounds are pivotal in elimination of ingested microbes but are also potent immunoregulatory compounds that suppress lymphocyte-mediated immunity [7], and NOX2-derived ROS are assumed to contribute in preventing autoimmune manifestations [8,9]. In addition, extracellular ROS, released from normal myeloid cells [10] as well as from myeloid-derived suppressor cells [11], tumor-associated macrophages [12] and malignant myeloid cells [1316] have been proposed to contribute to cancer-related immunosuppression in several malignancies, including leukemia. 
In B cell malignancies, myeloid cells have been proposed to reduce NK cell-mediated cytotoxicity against CD20-opsonized targets by metalloproteinasemediated shaving [17] or by extraction of the antibodybound CD20 antigen by trogocytosis [18]. In addition, it was recently reported that CD20 antibodies triggered neutrophils to release extracellular ROS [19], but the impact of antibody-triggered ROS on NK cell ADCC is not known. For this study, we hypothesized that reducing myeloid cell-derived ROS may improve the anti-leukemic efficacy of CD20 antibodies and thus investigated the impact of human $\mathrm{NOX}^{+}$monocytes on ADCC against human primary CLL cells in the presence or absence of anti-CD20 and anti-oxidative compounds. Our results suggest that monocytes produce and release significant amounts of ROS in response to both RTX and OFA. The ROS production limited the NK cell-mediated ADCC against primary leukemic cells, as NK cell ADCC could be partially restored by anti-oxidative agents. We propose that monocyte-mediated suppressive mechanisms, including trogocytosis and release of immunosuppressive ROS, may limit the benefit of anti-CD20 mAbs, and that anti-oxidative strategies may be of value to enhance the clinical efficacy of anti-CD20 therapy.

\section{RESULTS AND DISCUSSION}

In a first series of experiments we investigated whether CD20 mAbs mount an oxidative response from monocytes. As shown in Figure 1, RTX and OFA triggered
A

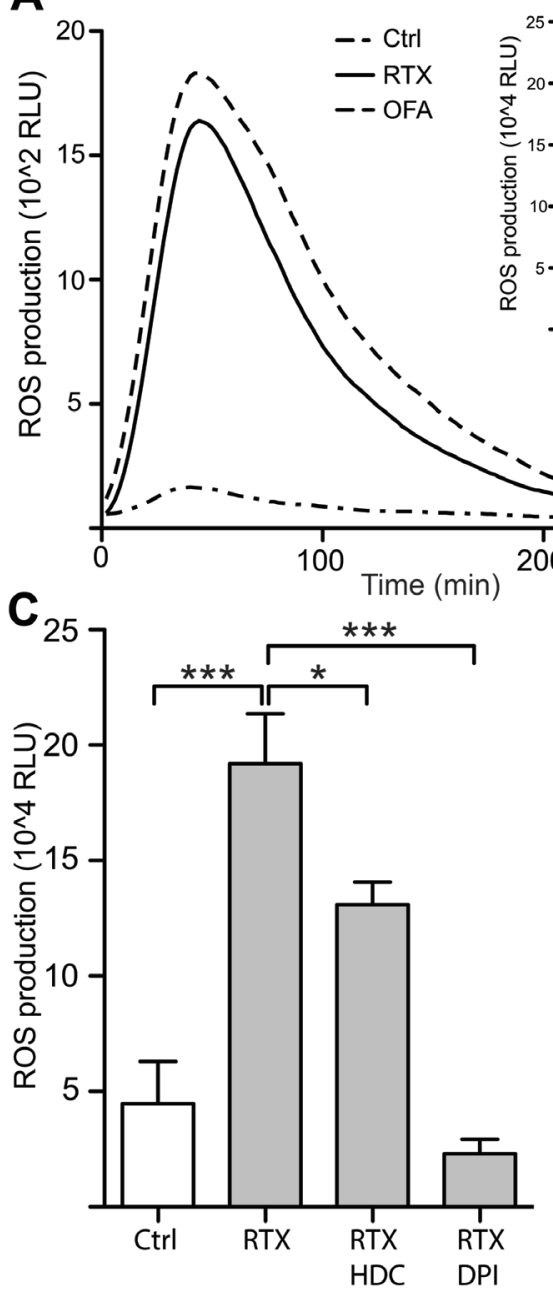

B

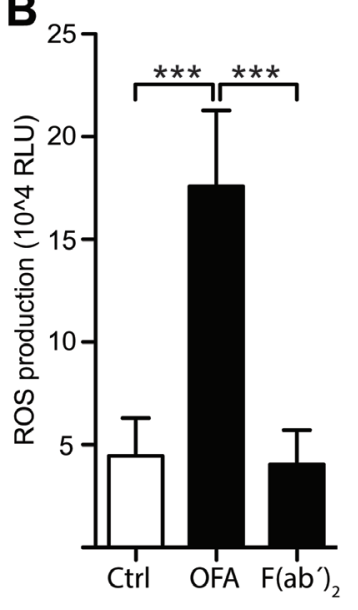

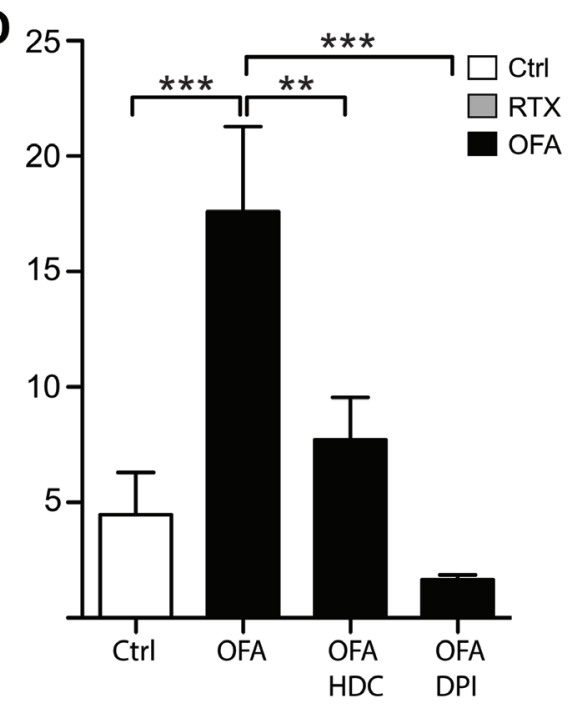

Figure 1: Rituximab and Ofatumumab triggered ROS production by monocytes. Monocytes derived from healthy blood donors were continuously assessed for extracellular ROS production by chemiluminescense in the presence of CLL cells (Mo:CLL ratio $2: 1)$ and the presence or absence of CD20 mAbs $(10 \mu \mathrm{g} / \mathrm{ml})$. A. shows a representative kinetic graph, while the inset column diagram shows total ROS production (Area Under Curve; AUC; $n=4)$. B. shows total ROS production in presence and absence of OFA $(10 \mu \mathrm{g}$ / $\mathrm{ml})$ and OFA-derived $\mathrm{F}\left(\mathrm{ab}^{\prime}\right)_{2}$ fragments $(10 \mu \mathrm{g} / \mathrm{ml})$. C., D. Total ROS production in presence and absence of the ROS formation inhibitors histamine dihydrochloride $(\mathrm{HDC} ; 100 \mu \mathrm{M})$ and diphenylene iodonium chloride (DPI; $3 \mu \mathrm{M})(n=4)$. Statistical significance for all figures was determined by one-way ANOVAs and the Bonferroni post test. (RLU;relative light units) $* p<0.05, * * p<0.01, * * * p<0.001$. 
a pronounced release of extracellular ROS from purified monocytes. The ROS production was mediated by NOX2, as inhibitors of this enzyme, HDC and DPI [20, 21], prevented the antibody-induced ROS formation. To clarify the role of Fc receptors and for the antibody-induced formation of ROS, we generated $\left.\mathrm{F}(\mathrm{ab})_{2}\right)_{2}$ fragments of ofatumumab and found that $\left.\mathrm{F}(\mathrm{ab})_{2}\right)_{2}$ fragments did not induce ROS, thus implying that monocytes produce ROS upon attaching to the FC-part of anti-CD20 Ab (Figure 1A).
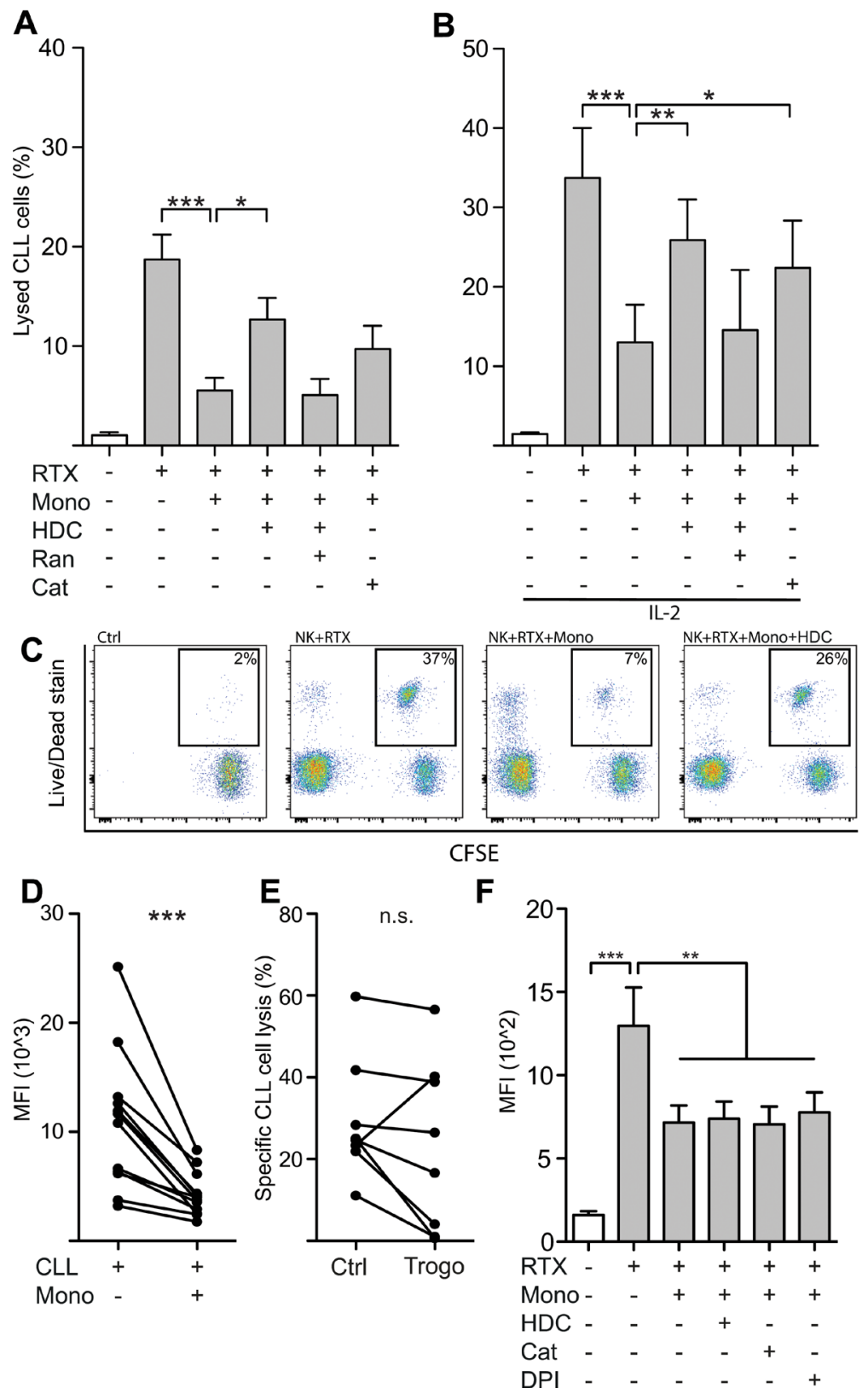

Figure 2: Monocytes restricted NK cell ADCC against autologous leukemic cells by production of ROS. A., B. NK cells and CFSE-labeled CLL cells were co-cultured for four hours in the presence or absence of autologous monocytes at an NK:Mo:CLL-ratio of 2:2:1 and IL-2 $(500 \mathrm{IU} / \mathrm{ml})$, rituximab $(10 \mu \mathrm{g} / \mathrm{ml})$, HDC $(100 \mu \mathrm{M})$, ranitidine (Ran; $100 \mu \mathrm{M})$ or catalase (Cat; 200IU/ml). ADCC was inhibited by the presence of monocytes, but largely restored by anti-oxidative agents HDC or catalase. $(n=5-7)$. C. Representative dot-plot depicting the read-out for lysed leukemic cells of panels A and B. Percentages denote the proportion of lysed leukemic cells, thus staining positive for the Live/Dead stain. D. Monocytes were found to decrease the density of surface-bound rituximab on CLL cells, a mechanism referred to as trogocytosis. E. NK cell-mediated ADCC of CLL cells previously exposed to monocytes, and thus allowing for antigen removal by trogocytosis, was lowered in 7 out of 8 performed experiments. F. Monocyte-mediated trogocytosis was unaffected by addition of anti-oxidative substances $(n=4) . * p<0.05, * * p<0.01, * * * p<0.001$. 
We next determined whether the presence of monocytes interfered with NK cell-mediated killing of autologous CLL cells. In accordance with earlier reports [22, 23], NK cells isolated from CLL patients induced significant CLL cell death in the presence of RTX with only minor cytotoxicity in the absence of a linking antibody. Monocytes failed to exert substantial RTX-dependent cytotoxicity against CLL cells. Instead, NK cell ADCC was strongly reduced in the presence of monocytes (Figure 2A-2B). HDC and the ROS-degrading enzyme catalase both partially restored the diminished ADCC of NK cells. Neither HDC nor catalase affected CLL cell viability or ADCC by NK cells in the absence of monocytes (data not shown). The NK cell-activating cytokine IL-2 augmented RTX-mediated ADCC by NK cells but did not rescue NK cells from ROS-induced inhibition (Figure 2B). Similar results were obtained using OFA in ADCC assays (data not shown).
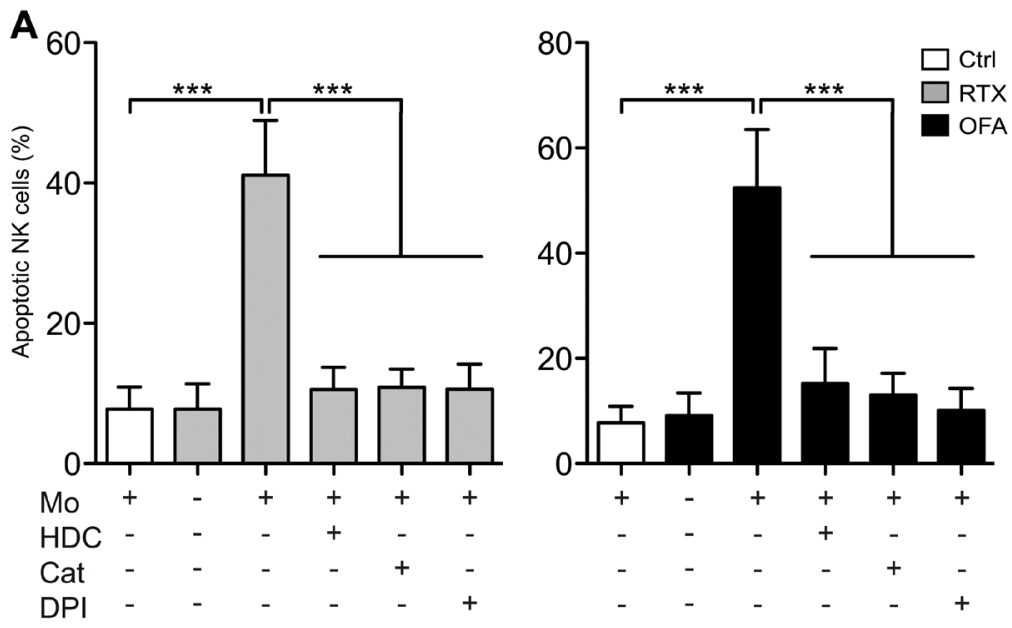

B
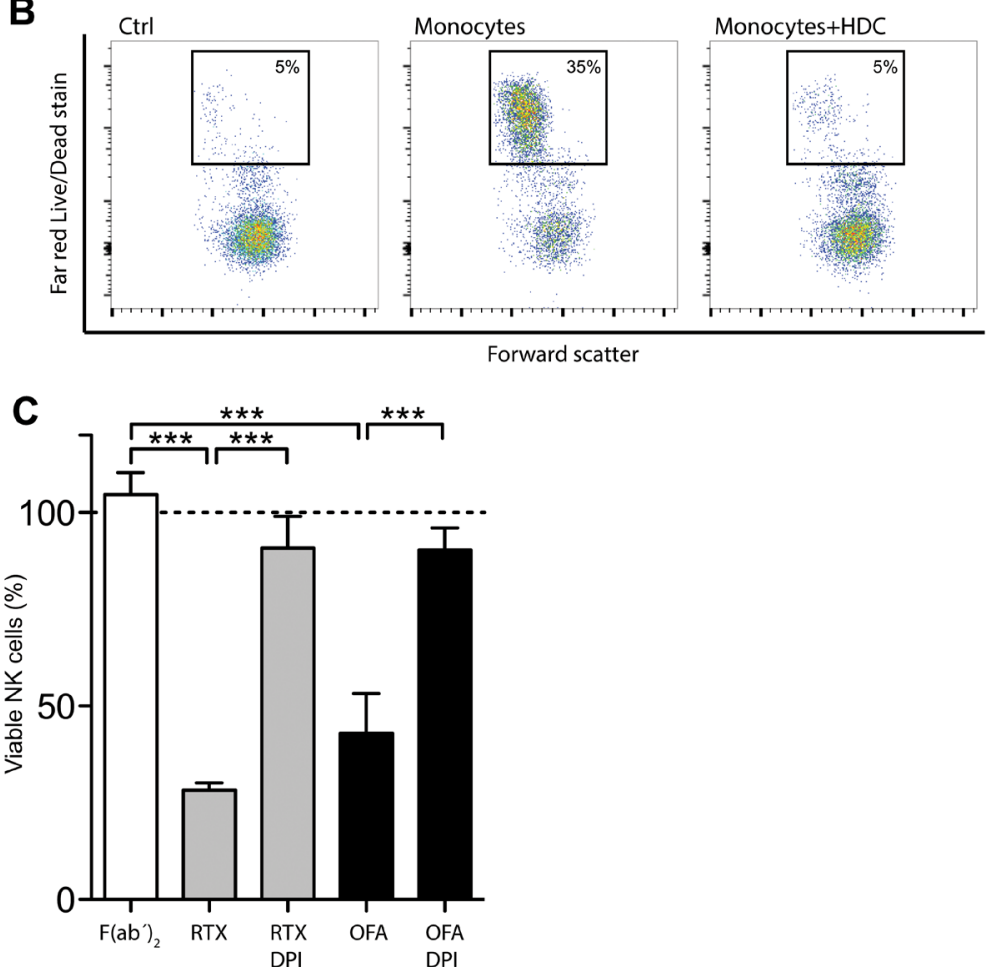

Figure 3: CD20 antibodies induced ROS-dependent NK cell apoptosis. A. NK cells and monocytes were co-cultured for 18 hours at a Mo:NK-ratio of 1:2 in presence or absence of immobilized, plate-bound RTX ( $5 \mu \mathrm{g} / \mathrm{ml}$; left) or OFA (5 $\mu \mathrm{g} / \mathrm{ml}$; right) and HDC $(100 \mu \mathrm{M})$, catalase $(200 \mathrm{IU} / \mathrm{ml})$ or DPI $(3 \mu \mathrm{M})(n=4)$. B. Representative dot-plot of the read-out for dead NK cells shown in panel A. C. PBMCs and PMNs at equal ratios were cultured for 18 hours in the presence or absence of plate-bound RTX, OFA or OFA- derived F(ab') $(10 \mu \mathrm{g} / \mathrm{ml})$ and DPI $(3 \mu \mathrm{M})$. Bars show percentage of remaining, viable CD 56 ${ }^{+}$CD3- NK cells compared to cultures with no antibody added (dotted line; $n=5$ ). ${ }^{* * *} p<0.001$. 
The incomplete restoration of cytotoxicity by anti-oxidative compounds suggested that additional mechanisms might have contributed to the observed inhibition of ADCC by monocytes. Previous studies have show that monocytes upon interaction with CD20 mAbopsonized CLL cells may shave off or extract the antibodyantigen complex from the CLL cells, a mechanism known as trogocytosis, thus reducing the amount of antibody bound to the CLL cells and limiting NK cell-mediated ADCC $[17,18]$. To address the impact of this inhibitory mechanism, we exposed CD20 mAb-opsonized CLL cells to monocytes and determined the level of bound antibody on CLL cells after 45 minutes of incubation. As shown in Figure 2D, monocytes reduced the amount of RTX bound to CLL cells. To investigate whether this reduction of bound antibody could explain the incomplete restoration of ADCC by antioxidative agents, we removed monocytes from the CLL cells using anti-CD14 beads, re-introduced RTX $(10 \mu \mathrm{g} / \mathrm{ml})$ and determined the CLL susceptibility to ADCC. As shown in Figure 2E, monocyte-induced trogocytosis of bound mAbs and antigens caused a slight, reduction of ADCC in 7 out of 8 experiments, though the observed reduction was not statistically significant. The addition of HDC, catalase or DPI did not affect the ability of monocytes to reduce RTX/OFA binding to CLL cells (Figure 2F). The restoration of ADCC observed in the presence of anti-oxidative substances was not due to inhibition of trogocytosis, but it is possible that trogocytosis, at least in part, could explain the incomplete restoration of ADCC by anti-oxidative reagents.

It was previously demonstrated that ROS produced from normal and leukemic myeloid cells trigger programmed cell death in NK cells [7, 14, 24, 25]. We thus investigated whether CD20 antibodies affected NK cell viability in the presence of ROS-producing monocytes. Using immobilized mAbs, which enable efficient crosslinking of Fc receptors and thus enhance the amplitude of transmitted signals, we observed that RTX and OFA induced extensive NK cell death, which was entirely prevented by HDC, DPI or catalase (Figure 3A). Similar results were obtained in experiments using leukocyte proportions aiming to mimic the situation in blood or bone marrow (Figure 3C). These findings support that ROS production by adjacent myeloid cells constitutes a negative regulator of $\mathrm{NK}$ cell function and that therapeutic CD20 antibodies reinforce myeloid cell-induced, ROSmediated immunosuppression, thus reducing the efficiency of the ADCC reaction.

Our results add to a growing body of evidence that proposes a role for myeloid cells in disease progression and maintenance of the leukemic clone in CLL. Burger and co-workers first described nurse-like cells, a population of monocyte-derived CD14 ${ }^{+}$cells that supported the survival of CLL cells in vitro [26]. Others reported that patients with CLL frequently harbor myeloid-derived suppressor cells (MDSCs) and that presence of these immunosuppressive, CD $14^{+} \mathrm{HLA}-\mathrm{DR}^{\text {lo }}$ monocytes in the peripheral blood is associated with advanced disease and poor prognosis $[27,28]$. In addition, Hanna et al. recently reported that depletion of monocytes in a mouse model of CLL resulted in significantly lower tumor burden [29]. Taken together, these reports highlight the myeloid compartment as a potential therapeutic target in CLL.

The NOX2 inhibitor HDC is used in conjunction with low-dose IL-2 as relapse-preventive immunotherapy in acute myeloid leukemia (AML), and the clinical efficacy of $\mathrm{HDC} / \mathrm{IL}-2$ is pronounced in $\mathrm{AML}$ with monocytic differentiation [13]. In vitro studies imply that patients with this subset of AML harbor malignant cells with capacity to produce extracellular ROS that inhibit adjacent NK cells [14]. Although CLL cells do not produce ROS, our finding that monocytes derived from patients with CLL are triggered to produce ROS by therapeutic antibodies suggests that a similar immunosuppressive environment may be operative in CLL during treatment with monoclonal antibodies. The anti-CD20-induced ROS-dependent suppression and apoptosis of NK cells induced by monocytes was inhibited by anti-oxidative agents, which translated into improved anti-leukemic efficacy. We propose further studies to clarify whether compounds that rescue NK cells from ROS-induced inactivation may improve the clinical efficacy of $\mathrm{mAb}$ based therapy in CLL.

\section{MATERIALS AND METHODS}

\section{Isolation of cells}

Blood samples from patients with CLL were collected after informed consent. Leukopacks from healthy blood donors were obtained from the Blood Center at Sahlgrenska University Hospital. Peripheral blood mononuclear cells (PBMC) and polymorphonuclear cells $(\mathrm{PMN})$ were isolated using dextran sedimentation followed by density gradient centrifugation and lysis of remaining erythrocytes by deionized water. PBMCs obtained from CLL patients were stained with antibodies, and $\mathrm{CD}^{-} / \mathrm{CD}^{2} 6^{+} \mathrm{NK}$ cells and $\mathrm{CD} 14^{+}$monocytes were FACS-sorted using a BD FACSAria III. For isolation of malignant CLL cells a Bcell (B-CLL) isolation kit was used according to the manufacturer's instructions (Purity $>90 \%$; Miltenyi Biotec). NK cells and monocytes were isolated from blood donor PBMCs by use of the corresponding MACS isolation kits (purity $>95 \%$ and 92\%, respectively; Miltenyi Biotec). 


\section{Generation of $F\left(a b^{\prime}\right)_{2}$ fragments}

$\mathrm{F}\left(\mathrm{ab}^{\prime}\right)_{2}$ fragments of ofatumumab were prepared by pepsin digestion using Pierce $\mathrm{F}\left(\mathrm{ab}^{\prime}\right)_{2}$ preparation kit \#44988 (Life Technologies) according to instructions provided by the manufacturer. Digestion and purity were confirmed by SDS-PAGE (Life Technologies).

\section{ROS production}

Extracellular ROS production by monocytes was assessed by chemiluminescence as described in detail elsewhere [14]. In brief, $2 * 10^{5}$ monocytes were suspended in Krebs-Ringer Glucose buffer supplemented with isoluminol $(10 \mu \mathrm{g} / \mathrm{ml})$ and horseradish peroxidase (4 U/ $\mathrm{ml})$. Monocytes were incubated at $37^{\circ} \mathrm{C}$ in the presence or absence of mAbs $(10 \mu \mathrm{g} / \mathrm{ml})$ and primary CLL cells, and the release of ROS (light emission) was continuously monitored using a BMG FLUOStar Microplate Reader. In some experiments, ofatumumab $\mathrm{F}\left(\mathrm{ab}^{\prime}\right)_{2}$ fragments were used to define the role of the $\mathrm{Fc}$ portion.

\section{NK cell death}

NK cells and monocytes were co-cultured overnight at various ratios (NK cell absolute count $2 * 10^{5}$ ) at $37^{\circ} \mathrm{C}$ and $5 \% \mathrm{CO}_{2}$ in the presence or absence of immobilized $\mathrm{mAbs}(5 \mu \mathrm{g} / \mathrm{ml})$ and anti-oxidative compounds. NK cell death was determined by flow cytometry after staining with a LIVE/DEAD ${ }^{\circledR}$ cell stain kit (Life Technologies). In some experiments leukocyte suspensions with physiologic cell proportions (adding an equal amount of PMNs to isolated PBMCs) were used (RTX and OFA $10 \mu \mathrm{g} / \mathrm{ml}$ ). In these experiments, $\mathrm{NK}$ cells were identified as $\mathrm{CD} 3{ }^{-} \mathrm{CD} 56^{+}$ lymphocytes, and fluorescent counting beads were used to determine the number of surviving NK cells.

\section{ADCC assays}

Isolated primary CLL cells were labeled with CFSE (Life Technologies) for traceability. Autologous NK cells, monocytes and CLL cells were co-cultured at a 2:2:1 ratio (absolute counts of $5^{*} 10^{4}$ for NK cells and monocytes and $2.5^{*} 10^{4}$ for CLL cells) in presence or absence of rituximab $(10 \mu \mathrm{g} / \mathrm{ml})$ and anti-oxidative compounds and incubated at $37^{\circ} \mathrm{C}$ and $5 \% \mathrm{CO}_{2}$. After four hours the cells were stained with a LIVE/DEAD ${ }^{\circledR}$ cell stain and assessed for target cell death by flow cytometry. In experiments with ofatumumab $(10 \mu \mathrm{g} / \mathrm{ml}) \mathrm{NK}$ cells and monocytes derived from healthy donor samples were used.

\section{Trogocytosis assay}

Isolated primary CLL cells were labeled with CellTrace Violet (Life Technologies) and incubated at $37^{\circ} \mathrm{C}$ and $5 \% \mathrm{CO}_{2}$ with rituximab $(10 \mu \mathrm{g} / \mathrm{ml})$ for $30 \mathrm{~min}$. Freshly isolated monocytes and opsonized CLL cells were co-cultured after a $15 \mathrm{~s}$ centrifugation $(300 \mathrm{~g})$ at a 2:1 ratio in a flat-bottomed $96-w e l l$ plate for $45 \mathrm{~min}$. In some experiments, monocytes were subsequently removed using IMag CD14 magnetic particles (BD Biosciences). CLL cells were stained with an anti-IgG FITC antibody (Jackson ImmunoResearch) and assessed for RTXbound CD20 expression by flow cytometry. In some experiments, CLL cells previously exposed to monocytes were subjected to an ADCC assay using freshly isolated NK cells and rituximab $(10 \mu \mathrm{g} / \mathrm{ml})$ as described above.

\section{Compounds}

The following compounds were used: rituximab (RTX; Roche), ofatumumab (OFA; GSK), histamine dihydrochloride (HDC; $100 \mu \mathrm{M})$, ranitidine $(100 \mu \mathrm{M})$, catalase (200U/ml), interleukin-2 (IL-2; 500U/ml; Chiron) and diphenylene iodonium chloride (DPI; $3 \mu \mathrm{M}$; Sigma).

\section{Ethics}

This study was approved by the ethical review board of Gothenburg. All experiments were performed in accordance with the Declaration of Helsinki.

\section{ACKNOWLEDGMENTS}

The authors thank the patients for their participation in this study, and Veronica Osla and Ulla Gingsjö for technical assistance.

\section{CONFLICTS OF INTEREST}

Author KH holds patents protecting the use of histamine dihydrochloride in cancer immunotherapy. The other authors declare no potential conflicts of interest.

\section{Authorship}

FBT was the principal investigator; JA, AM, KH and FBT designed the research; OW, JA, AH, AAA and MS performed experiments; OW performed statistical analyses and drafted the figures; OW and POA recruited patients; OW, AM, KH and FBT wrote the manuscript; all authors contributed in interpreting data and editing the manuscript. 


\section{GRANT SUPPORT}

This work was supported by the Swedish Research Council (2011-3003), the Swedish Cancer Society (CAN 213/550), the Swedish state via the ALF agreement (ALFGBG-292701), BioCARE - a National Strategic Research Program at University of Gothenburg, and the Sahlgrenska Academy at University of Gothenburg, The Gothenburg Medical Society, The Assar Gabrielsson Foundation and The Wilhelm and Martina Lundgren Research Foundation.

\section{Editorial note}

This paper has been accepted based in part on peerreview conducted by another journal and the authors' response and revisions as well as expedited peer-review in Oncotarget.

\section{REFERENCES}

1. Alduaij $\mathrm{W}$ and Illidge TM. The future of anti-CD20 monoclonal antibodies: are we making progress? Blood. 2011; 117:2993-3001.

2. Cartron G, Dacheux L, Salles G, Solal-Celigny P, Bardos $\mathrm{P}$, Colombat $\mathrm{P}$ and Watier $\mathrm{H}$. Therapeutic activity of humanized anti-CD20 monoclonal antibody and polymorphism in IgG Fc receptor FcgammaRIIIa gene. Blood. 2002; 99:754-758.

3. Du J, Lopez-Verges S, Pitcher BN, Johnson J, Jung SH, Zhou L, Hsu K, Czuczman MS, Cheson B, Kaplan L, Lanier LL and Venstrom JM. CALGB 150905 (Alliance): rituximab broadens the antilymphoma response by activating unlicensed NK cells. Cancer immunology research. 2014; 2:878-889.

4. Weng WK, Negrin RS, Lavori P and Horning SJ. Immunoglobulin G Fe receptor FcgammaRIIIa 158 V/F polymorphism correlates with rituximab-induced neutropenia after autologous transplantation in patients with non-Hodgkin's lymphoma. Journal of clinical oncology. 2010; 28:279-284.

5. Katrinakis G, Kyriakou D, Papadaki H, Kalokyri I, Markidou F and Eliopoulos GD. Defective natural killer cell activity in B-cell chronic lymphocytic leukaemia is associated with impaired release of natural killer cytotoxic factor(s) but not of tumour necrosis factor-alpha. Acta Haematol. 1996; 96:16-23.

6. Kay NE and Zarling JM. Impaired natural killer activity in patients with chronic lymphocytic leukemia is associated with a deficiency of azurophilic cytoplasmic granules in putative NK cells. Blood. 1984; 63:305-309.

7. Hansson M, Asea A, Ersson U, Hermodsson $S$ and Hellstrand K. Induction of apoptosis in NK cells by monocyte-derived reactive oxygen metabolites. J Immunol.
$1996 ; 156: 42-47$.

8. Hultqvist M, Olsson LM, Gelderman KA and Holmdahl R. The protective role of ROS in autoimmune disease. Trends Immunol. 2009; 30:201-208.

9. Holmdahl R, Sareila O, Pizzolla A, Winter S, Hagert C, Jaakkola N, Kelkka T, Olsson LM, Wing K and Backdahl L. Hydrogen peroxide as an immunological transmitter regulating autoreactive T cells. Antioxid Redox Signal. 2013; 18:1463-1474.

10. Hellstrand K, Asea A, Dahlgren C and Hermodsson S. Histaminergic regulation of NK cells. Role of monocytederived reactive oxygen metabolites. J Immunol. 1994; 153:4940-4947.

11. Corzo CA, Cotter MJ, Cheng P, Cheng F, Kusmartsev S, Sotomayor E, Padhya T, McCaffrey TV, McCaffrey JC and Gabrilovich DI. Mechanism regulating reactive oxygen species in tumor-induced myeloid-derived suppressor cells. J Immunol. 2009; 182:5693-5701.

12. Kono K, Salazar-Onfray F, Petersson M, Hansson J, Masucci G, Wasserman K, Nakazawa T, Anderson P and Kiessling R. Hydrogen peroxide secreted by tumor-derived macrophages down-modulates signal-transducing zeta molecules and inhibits tumor-specific $\mathrm{T}$ cell-and natural killer cell-mediated cytotoxicity. Eur J Immunol. 1996; 26:1308-1313.

13. Aurelius J, Martner A, Brune M, Palmqvist L, Hansson M, Hellstrand K and Thoren FB. Remission maintenance in acute myeloid leukemia: impact of functional histamine H2 receptors expressed by leukemic cells. Haematologica. 2012.

14. Aurelius J, Thoren FB, Akhiani AA, Brune M, Palmqvist L, Hansson M, Hellstrand K and Martner A. Monocytic AML cells inactivate antileukemic lymphocytes: role of NADPH oxidase/gp91(phox) expression and the PARP-1/ PAR pathway of apoptosis. Blood. 2012; 119:5832-5837.

15. Mellqvist UH, Hansson M, Brune M, Dahlgren C, Hermodsson S and Hellstrand K. Natural killer cell dysfunction and apoptosis induced by chronic myelogenous leukemia cells: role of reactive oxygen species and regulation by histamine. Blood. 2000; 96:1961-1968.

16. Aurelius J, Martner A, Riise RE, Romero AI, Palmqvist L, Brune M, Hellstrand K and Thoren FB. Chronic myeloid leukemic cells trigger poly(ADP-ribose) polymerasedependent inactivation and cell death in lymphocytes. J Leukoc Biol. 2013; 93:155-160.

17. Beum PV, Lindorfer MA and Taylor RP. Within peripheral blood mononuclear cells, antibody-dependent cellular cytotoxicity of rituximab-opsonized Daudi cells is promoted by NK cells and inhibited by monocytes due to shaving. J Immunol. 2008; 181:2916-2924.

18. Taylor RP and Lindorfer MA. Fcgamma-receptor-mediated trogocytosis impacts mAb-based therapies: historical precedence and recent developments. Blood. 2015; 125:762-766. 
19. Werlenius O, Riise RE, Simpanen M, Aurelius J and Thoren FB. CD20 antibodies induce production and release of reactive oxygen species by neutrophils. Blood. 2014; 123:4001-4002.

20. Hellstrand K, Brune M, Dahlgren C, Hansson M, Hermodsson S, Lindner P, Mellqvist UH and Naredi P. Alleviating oxidative stress in cancer immunotherapy: a role for histamine? Med Oncol. 2000; 17:258-269.

21. O'Donnell BV, Tew DG, Jones OT and England PJ. Studies on the inhibitory mechanism of iodonium compounds with special reference to neutrophil NADPH oxidase. Biochem J. 1993; 290:41-49.

22. Golay J, Manganini M, Facchinetti V, Gramigna R, Broady R, Borleri G, Rambaldi A and Introna M. Rituximabmediated antibody-dependent cellular cytotoxicity against neoplastic B cells is stimulated strongly by interleukin- 2 . Haematologica. 2003; 88:1002-1012.

23. Veuillen C, Aurran-Schleinitz T, Castellano R, Rey J, Mallet F, Orlanducci F, Pouyet L, Just-Landi S, Coso D, Ivanov V, Carcopino X, Bouabdallah R, Collette Y, Fauriat C and Olive D. Primary B-CLL resistance to NK cell cytotoxicity can be overcome in vitro and in vivo by priming NK cells and monoclonal antibody therapy. Journal of clinical immunology. 2012; 32:632-646.

24. Thoren FB, Romero AI and Hellstrand K. Oxygen radicals induce poly(ADP-ribose) polymerase-dependent cell death in cytotoxic lymphocytes. J Immunol. 2006; 176:73017307.
25. Thoren FB, Romero AI, Hermodsson S and Hellstrand K. The CD16-/CD56bright subset of NK cells is resistant to oxidant-induced cell death. J Immunol. 2007; 179:781-785.

26. Burger JA, Tsukada N, Burger M, Zvaifler NJ, Dell'Aquila $\mathrm{M}$ and Kipps TJ. Blood-derived nurse-like cells protect chronic lymphocytic leukemia B cells from spontaneous apoptosis through stromal cell-derived factor-1. Blood. 2000; 96:2655-2663.

27. Gustafson MP, Abraham RS, Lin Y, Wu W, Gastineau DA, Zent CS and Dietz AB. Association of an increased frequency of CD14+ HLA-DR lo/neg monocytes with decreased time to progression in chronic lymphocytic leukaemia (CLL). Br J Haematol. 2012; 156:674-676.

28. Jitschin R, Braun M, Buttner M, Dettmer-Wilde K, Bricks J, Berger J, Eckart MJ, Krause SW, Oefner PJ, Le Blanc K, Mackensen A and Mougiakakos D. CLL-cells induce IDOhi CD14+HLA-DRlo myeloid-derived suppressor cells that inhibit T-cell responses and promote TRegs. Blood. 2014; 124:750-760.

29. Hanna BS, McClanahan F, Yazdanparast H, Zaborsky N, Kalter V, Rossner PM, Benner A, Durr C, Egle A, Gribben JG, Lichter P and Seiffert M. Depletion of CLL-associated patrolling monocytes and macrophages controls disease development and repairs immune dysfunction in vivo. Leukemia. 2016; 30:570-579. 